\title{
Technical diagnostics of the historic apartment house located at No. 31 in Dobra street in Warsaw
}

\author{
Michat Bukała ${ }^{1}$, Andrzej Chyła ${ }^{1}$, Leopold $\mathrm{Kruszka}^{2}$, Pawet Muzolf $^{2, *}$ \\ ${ }^{1}$ SVANTEK Ltd, Warsaw, Poland. \\ ${ }^{2}$ Faculty of Civil Engineering and Geodesy, Military University of Technology, Warsaw, Poland.
}

\begin{abstract}
This paper presents a case study of investigating damage and assessing the current detailed technical state of the historic apartment house located at No. 31 in Dobra Street in Warsaw. The purpose of this assessment is to determine the possibility of the reconstruction of its last overground storey and the utility attic. Moreover, the impact of the second underground line construction process and the influence of transport vibrations caused by both the street traffic and the underground on the damage of the supporting structure of the building is determined. The study was conducted in order to prepare the design for the planned last overground storey reconstruction considering the influence of the construction process on the adjacent buildings and the surrounding urbanized area. The study of the building documentation and the field investigation on damage in the existing building allow the authors to conclude that the current technical condition of this building does not exclude the possibility of making the superstructure of this building. Moreover, the results of the carried out vibrations transmitted by the ground to the load-bearing structure of this building show that neither the transport-caused vibrations nor the noise do not cause a harmful effect both on the damaged masonry supporting structure of this building, as well as on its residents. The conditions of reconstruction of this historic building are also specified in this paper.
\end{abstract}

\section{Introduction}

One of the most serious problems of traditional buildings, including the historic and worn out, operated buildings, is the formation of scratches and cracks in masonry elements of the supporting structure [1]. The structural damage in load-bearing walls may arise as a result of uneven settlement of the building, local exceeding of the permissible stresses (e.g. the increasing of the operational load), the loss of stability and longitudinal stiffness of the walls, as well as due to the thermal stresses caused by temperature changes. The above mentioned issues especially refer to the brick load-bearing walls of several-decade-old historic buildings, particularly with classic wooden or ceramic Klein ceilings. During the period of their construction, ring beams were not made in the level of ceilings between floors. These

\footnotetext{
*Corresponding author: pawel.muzolf@,wat.edu.pl
} 
ring beams, usually in the form of steel reinforced concrete beams, ensure horizontal supports of the construction and provide the tensile strength that is missing in brickwork. The further utilization and operation of these historic buildings in which ring beams were not applied and with such structural damage, without proper maintenance management may lead to a real risk to life and health of their users in a relatively short period of time.

The article presents the assessment of the technical state of the historic apartment house located at No. 31 in Dobra Street in Warsaw. The purpose of this assessment is to determine the possibility of the reconstruction of its last overground storey and the utility attic. Moreover, the impact of the 2nd underground line construction process and the influence of transport vibrations caused by both the street traffic and the underground on the damage of the supporting structure of the building is determined. Finally, the analysis and considerations were used to present the detailed recommendations related to the determination of the methods of carrying-out construction works, as well as their scope.

\section{Description of the technical condition of the building structure}

\subsection{Building structure and historical outline}

The analysed building is a part of the terraced and front row building development, in the plan drawing marked with the letter " $\mathrm{C}$ ", with the main wing from the side of Dobra Street and the side wing from the side of Zajęcza Street with its outbuilding perpendicular to it in the yard - Fig. 1 .

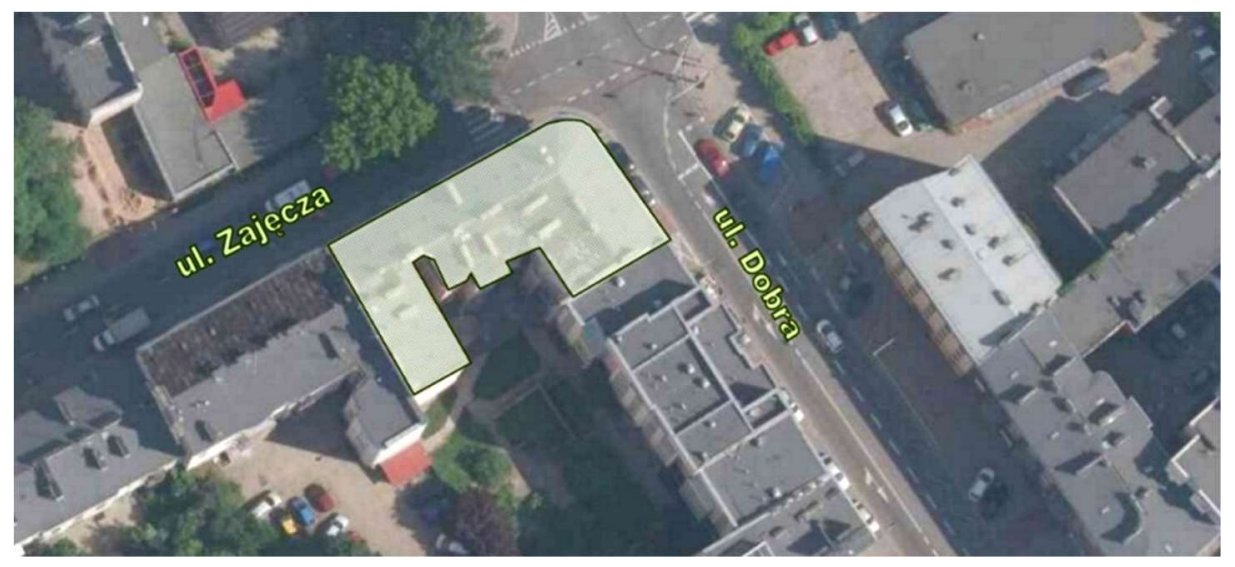

Fig. 1. The location of the residential building [2].

The building of the so called apartment house of the Matysiak Family, was erected around 1920. The changes in the construction status in the location of No. 31 in Dobra Street in the years 1935-2015 are shown in Fig. 2. The pre-war photographs of the building made in 193545 come from the sources of the State Archives in Warsaw (Warsaw City Files, Municipal Board in the Capital City of Warsaw, Faculty City Planning, the so called "Referat Gabarytów").

During the Second World War the building was partially destroyed. After the war, the apartment house was rebuilt, reduced by one floor and it also lost the crowning of the corner in the form of a turret - Fig. 3. Then it was operated as a municipal building. 

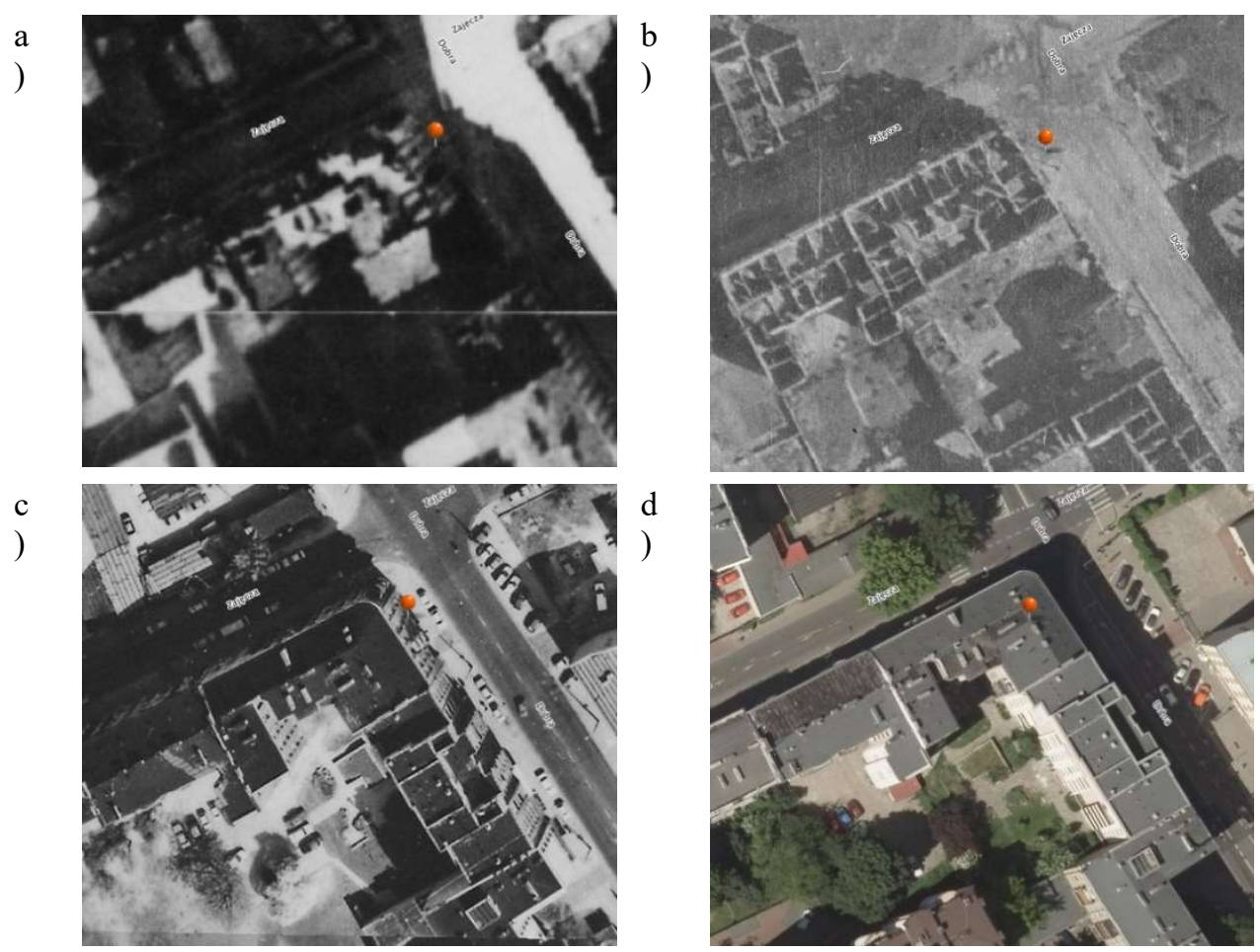

Fig. 2. The condition of the building development at No. 31 in Dobra Street in: a) 1935, b) 1945, c) 1990,d) 2015 [3].

Currently, the building has five floors above the ground level and one underground floor. The supporting structure of the building is of a traditional brick type with a longwall construction system. The shape of the building and the variable layout make the building have a different spatial rigidity. Moreover, the cut-out of the recess at the interface between the walls of the front part and the annex adjacent to the yard cause the weakening of this rigidity.

a

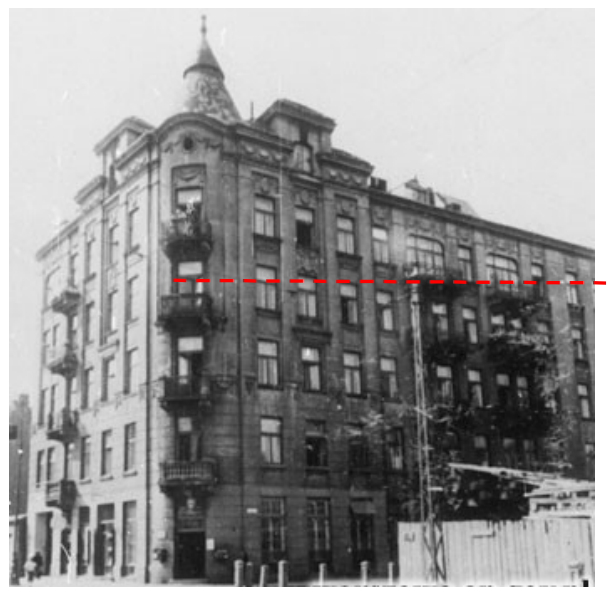

b)

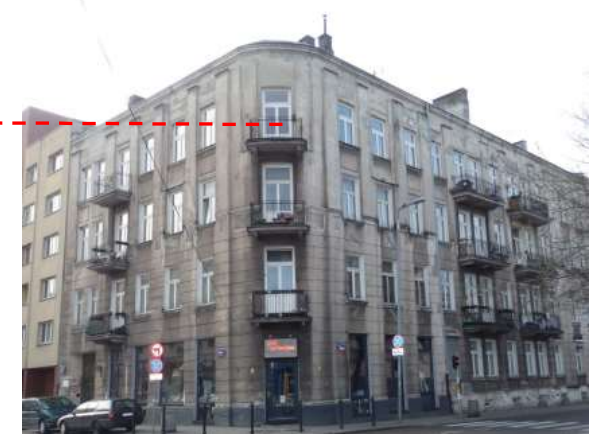

Fig. 3. The general_ view of the building from the crossroads of Dobra and Zajęcza Streets: a) the pre-war state [4], b) the state in 2016 , [the author's photographs]. 


\subsection{Field inspection of the building}

In order to assess the technical state of the building and to prepare the design for the planned last overground storey reconstruction, a detailed technical inspection of the building as well as macroscopic "in situ" tests were conducted by the authors. The damage of structural elements and numerous vertical cracks in the brick walls with a width of approx. $1 \div 3 \mathrm{~mm}$ that could can have a significant impact on the building's safety during the repair works were found. Figure 4 presents measured cracks on the front elevation from the side of Dobra and Zajęcza Streets. Moreover, cracks in the front-walls piers (Fig. 5), as well as cracks around the lintels (about $1 \div 3 \mathrm{~mm}$ ), and in the window sills (about $1 \div 3 \mathrm{~mm}$ ) - Fig. 6, were observed.

a)

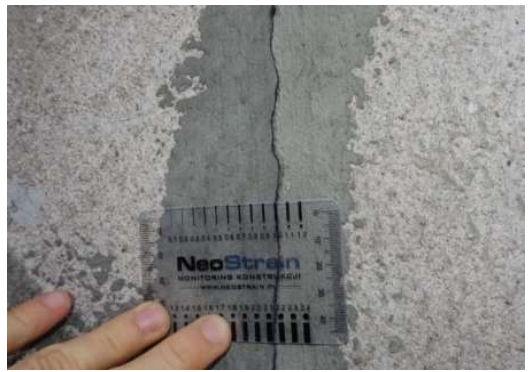

b)

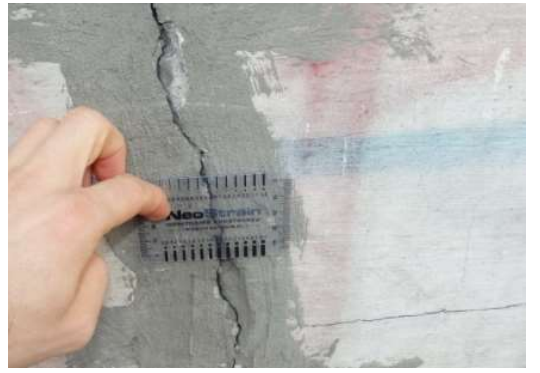

Fig. 4. The examples of the cracks on the façade from Zajęcza Street side: a) with a width of approx. 1 $\mathrm{mm}, \mathrm{b}$ ) with a width of approx. $2 \mathrm{~mm}$.

a)

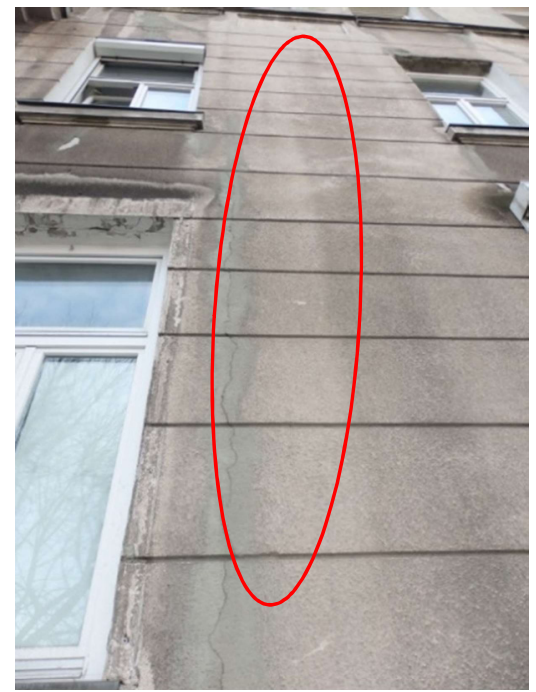

b)

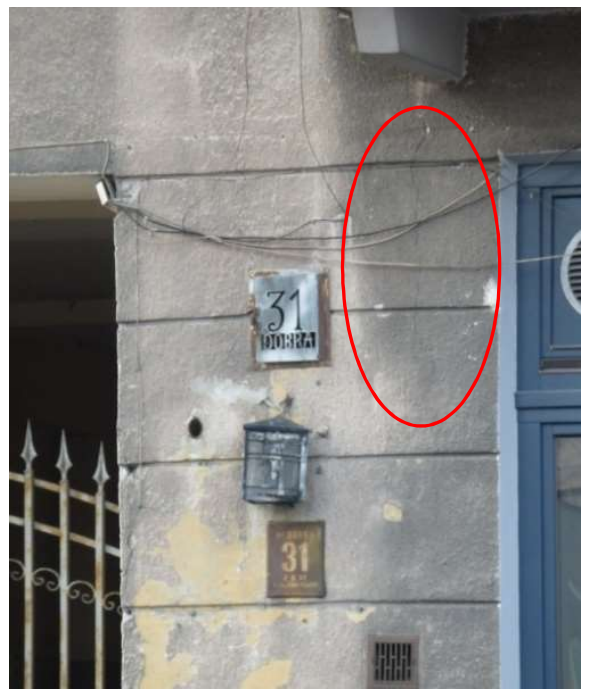

Fig. 5. The cracks observed: a) in the front-wall pier in Zajęcza Street (having the character of a reflected - secondary crack), b) a crack near the entrance gate from the side of Dobra Street. 

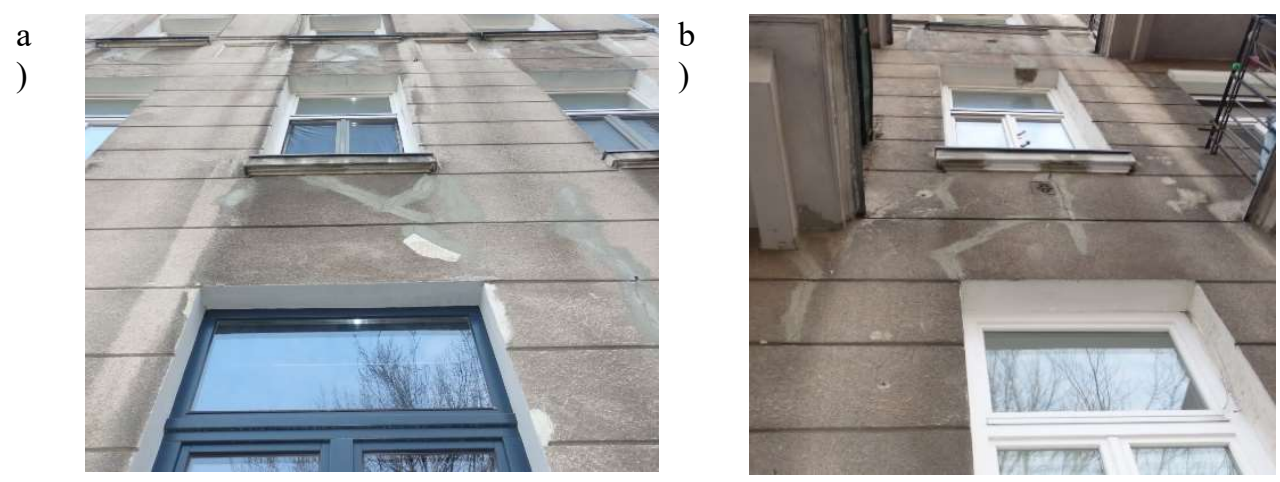

Fig. 6. The examples of scratches and cracks near the window lintels, the sub-front walls and near the balconies.

On the façade from the courtyard side, cornice cracks - both in the the plaster and the construction material were found (Fig. 7). Moreover, the vertical crack of the supporting wall from the backyard with a width of approx. $5 \div 8 \mathrm{~mm}$ (at the interface between the side wall and the outbuilding) - Fig. 8 , the cracks and the delamination along the steel edge beams of the balcony slabs (Fig. 9), the cracks in load-bearing walls and the window lintels with a width of approx. $2 \div 3 \mathrm{~mm}$, as well as the damaged and damp pedestals (the cracks, the cavities, the exposed walls, the places with the advanced corrosion) were noticed.
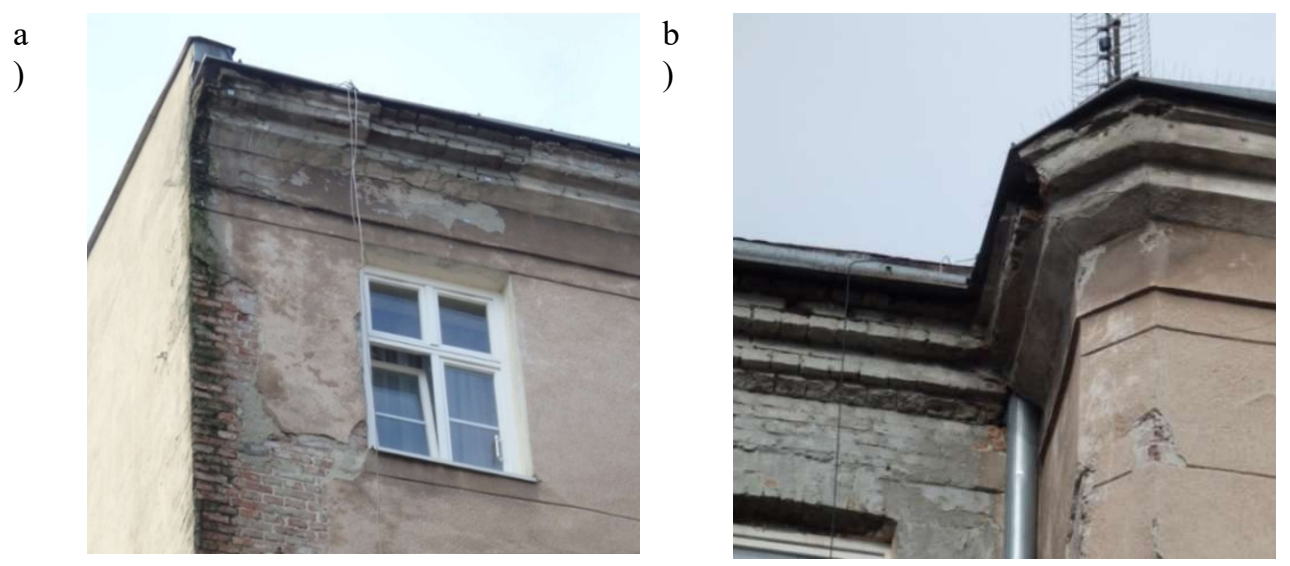

Fig. 7. Observed cracks in brick cornices.

With regard to staircases, the detailed inspections and conducted examinations confirmed the presence of the vertical and diagonal cracks in the structural walls of staircases with a width of approx. $1 \div 2 \mathrm{~mm}$ (Fig. 10) and a longitudinal crack in the staircase covered with grinded terrazzo with a width of approx. $2 \div 4 \mathrm{~mm}$ (Fig. 11). 


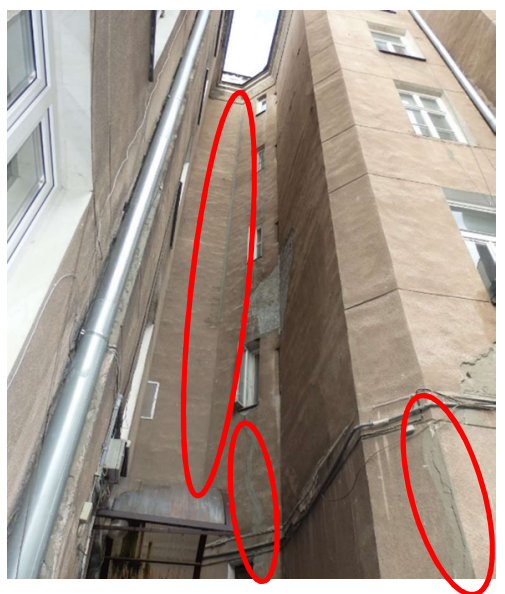

Fig. 8. The vertical crack of the supporting wall from the backyard with a width of approx. $5 \div 8 \mathrm{~mm}$. In addition, other visible cracks are also marked.

a

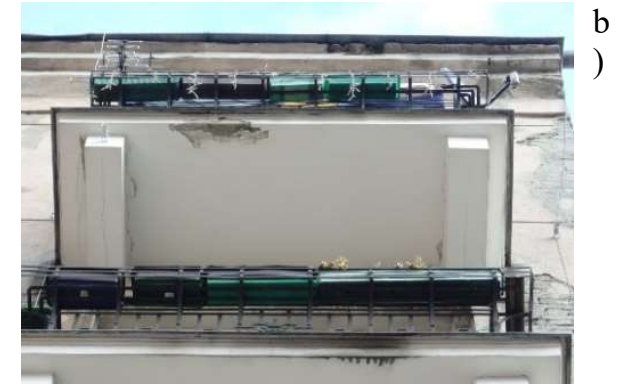

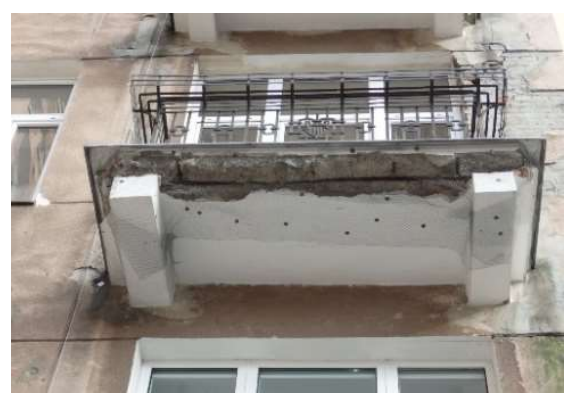

Fig. 9. Cracks and delamination along steel edge beams of balcony slabs.

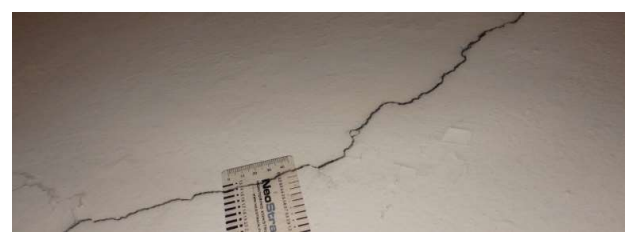

Fig. 10. The example of a diagonal crack in the structural wall of staircases with a width of approx. 1 $\div 2 \mathrm{~mm}$.

a)

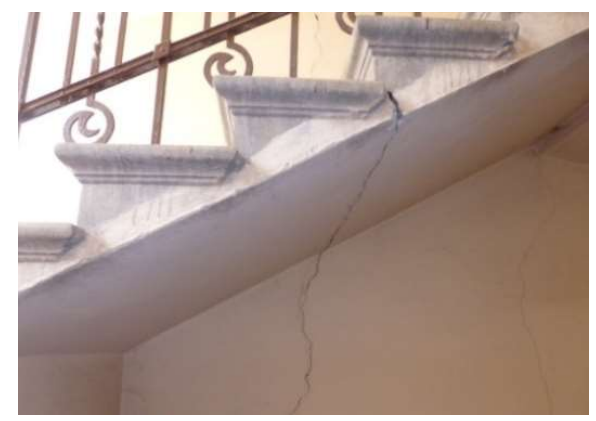

b)

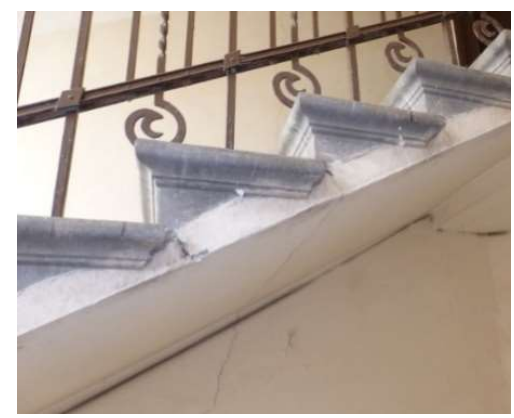

Fig. 11. The longitudinal crack in the staircase covered with grinded terrazzo with a width of approx. $2 \div 4 \mathrm{~mm}$ - the staircase in the front part of the building with the entrance from the main gate. 
The technical state of the elevation is found to be very poor due to the cracks and the chipping of the cornice plasters. Dampness and seepage under the cornices and balcony slabs were also observed, as well as plaster losses and the chipping of plinths. However, both above mentioned damages do not pose a threat to the safety of the structure.

Considering the appeared and observed damage, the technical condition of the building is classified in Class 4 according to the criteria set by the BRI (Building Research Institute in Poland). The classification of this building into the 4th class means "serious" damage, i.e. the cracks in the bearing walls with a width of $1 \div 5 \mathrm{~mm}$; the cracking of the external walls at window and door openings, connecting 3 holes of the width $>1 \mathrm{~mm}$, along the entire thickness of the wall; the crack $>1 \mathrm{~mm}$ of a length of more than 1 storey, the scratches of the ceilings along the beams, repeating vertically, with a width of 1 to $5 \mathrm{~mm}$, the scratches of the ceilings perpendicular to beams [5]. Additionally, according to the standards for determining the technical wear of buildings [6], the general technical state of the supporting structure of the building is assessed as "bad" (in the five-grade scale: very good, good, satisfactory, medium and bad). Due to the high percentage (about 60\%) of the technical wear of the building and its elements, it has been determined that a comprehensive repair of this construction is required together with the reinforcement of the damaged load-bearing structure in the perspective of the planned reconstruction works of the last overground storey. However, it should be emphasized that the damage found did not pose "a direct threat" to the safety of the load-bearing structure of the building.

\section{Assessment of the impact of the construction of the second underground line on the damages of the historic apartment house}

In order to assess the impact of the construction of the second underground line, archival technical documentation was used. One of the analysed documentation was a technical expertise prepared by an expert Zbigniew Tyczyński, whose task was to assess the condition of the building from before the commencement of the construction process - May 2006 [7]. The author described the technical state of the building as bad. However, that state neither posed a threat to the safety of the load-bearing structure nor to the safety of its users. The above study identifies two main causes of the building damages. The first indicated reason was the carrying out of the construction works related to the urban infrastructure along Dobra and Zajęcza Streets without the proper protection of the load-bearing structure of the building. The result of this works was the shift of the soil from beneath the foundations of the building's load-bearing walls to the resulting excavations, and as a consequence, even settlements of the load-bearing walls of the structure and the formation of scratches and cracks were caused. The second identified cause was the lack of leak-tightness of the sewage and the rainwater drainage system of the building. The author of the expertise recommended then to undertake major renovation works as soon as possible, from which only a part was realized. Except for a superficial repair of the linear damage (scratches and cracks) and a repair of surface damage, but without filling them with injections, a partial replacement of the rainwater drainage system was carried out. It should be stressed that the soil under the continuous footing of the load-bearing walls from the yard side was not reinforced and as a consequence no primary causes of cracks and damages were eliminated, especially taking into consideration the fact that the building did not have horizontal reinforcement in the form of ring beams.

The catalogue cards of the analysed building No. 4.19 [8] and No. C-50 [9] confirm the existence of the building damages in years 2007 and 2010, described previously in the expert report from 2006 [6], that is before the construction of the second underground line. It should be emphasized that these cards were attachments to the studies prepared by the team of Wojciech Wolski and AGP Metro Polska SC as a part of the construction design of the central 
section of the second underground line. These documents were developed at the request of the Warsaw Underground Ltd. to assess the technical state of the buildings in the zones affected by the construction of the second underground line in Warsaw on the section from the "Nowy Świat" to the "Dworzec Wileński" stations. Both teams assessing the technical condition of the building at No. 31. Dobra Street classified this facility to class 4 according to Building Research Institute in Poland (BRI) scale, i.e. as serious [5]. Moreover, the extensive photographic documentation presented in those studies confirms the existence of the building damages described in the present work.

Based on the analysis of the documents commissioned by the Metro Warszawskie Ltd and taking into account the existing expert knowledge on modern methods of making and drilling underground tunnels, including the used tunnelling technology TBM (Tunnel Boring Machines), it should be stated that the technologies of civil - engineering works used for the metro construction protected the building against the negative impact of the underground works. Although the building remained in the impact zone of the underground construction, the activities undertaken by the Contractor, such as the state-of-the-art tunnelling technology, geodetic monitoring, including current geodetic surveys, as well as the applied design solutions of tunnels and stations preserved the building against the propagation of damages also during the subsequent operation of the underground line. The use of TBM technology minimized the risk of settlement of the building site. Moreover, continuous monitoring of the construction zone enabled current analysis and interpretation of the results of geodetic measurements. The georeferencing system and the GIS (Geographic Information System) platform served to this purpose. Information generated and gathered by computers was interpreted by a team of experts who immediately responded to any irregularities and possible threats.

However, it should be emphasized that the results of the surveying monitoring performed by the Contractor during the construction works, as well as after reaching the final milestone of the tunnel-boring works, indicate that in the period of 30/09/2013 - 17/04/2014 (about 6 months) the supporting structure of the building at No. 31 in Dobra Street displaced a maximum of $-4.7 \mathrm{~mm}$, which is below the limit value of $5 \mathrm{~mm} \div 7 \mathrm{~mm}$ for brick buildings without ring beams and with wooden or ceramic ceilings of the Klein type [10]. For comparison, in the later period, i.e. 17/04/2014 - 13/05/2014 (period of about 13 months) the maximum displacement of $-0.3 \mathrm{~mm}$ was observed. For post-fact analysis of events, it is also crucial to inform that on 12/08/2013 and on 11/10/2013 the tunnel boring machines Krystyna and Elisabetta reached the Copernicus Science Centre station from the east side, respectively. On 22/10/2013, the western wall of the station was "crossed" by the Anna TBM and on 28/11/2013 the Maria TBM reached the Copernicus Science Centre station from the west side, thus marking the end of tunnelling works in the impact zone for the analysed building.

To sum up, the realization of this section of the second underground line construction in the period under consideration caused $-4.7 \mathrm{~mm}$ displacement (settlement) of the building, which is under the limit value $5 \mathrm{~mm} \div 7 \mathrm{~mm}$. This means that the conducted construction works did not significantly affect the deterioration of the technical condition of the building at No. 31 in Dobra Street because there were no significant changes in the morphology of the linear and surface damage areas, documented successively in 2006 and in 2010 in comparison with a picture of damages taken from inventory in this work. Insignificant changes in the morphology of damages during the operational time of the building result from the accelerated environmental wear of the damaged load-bearing structure of the building, including long-term impact of transportation vibrations, rather than from the execution of construction works on the section of the second underground line.

Interpreting the results of measurements of vibrations transmitted by the ground to the building at No. 31 in Dobra Street in Warsaw, made by the authors of this work, it was found that the vibrations caused by the operated underground line do not have a significant and 
harmful effect on the building elements and its structure. At point PD1, i.e. in the basement of the building from the side of Zajęcza Street, the values of vibration accelerations are ranged in zone I of the scale of dynamic influences SWD II (vibrations not perceptible by the building). - Fig. 12.

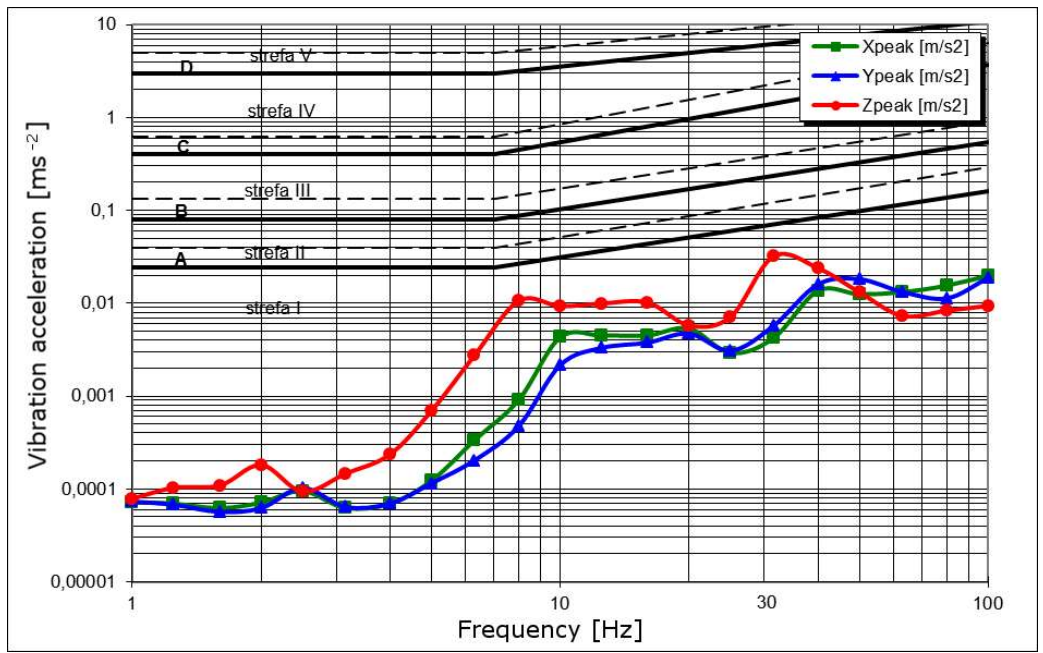

Fig. 12. The results of measurements of the impact of vibrations on building in $1 / 3$-octave bands for all axes at point PD1 (SWD II scale).

At point PD2, i.e. in the basement of the building from Dobra Street (cafe), vibrations of $50 \mathrm{~Hz}$ frequency are included in zone II of the SWD II scale (vibrations perceptible by the building, but harmless to the structure, accelerated building wear and first cracks in the plasters, etc.) - Fig. 13.

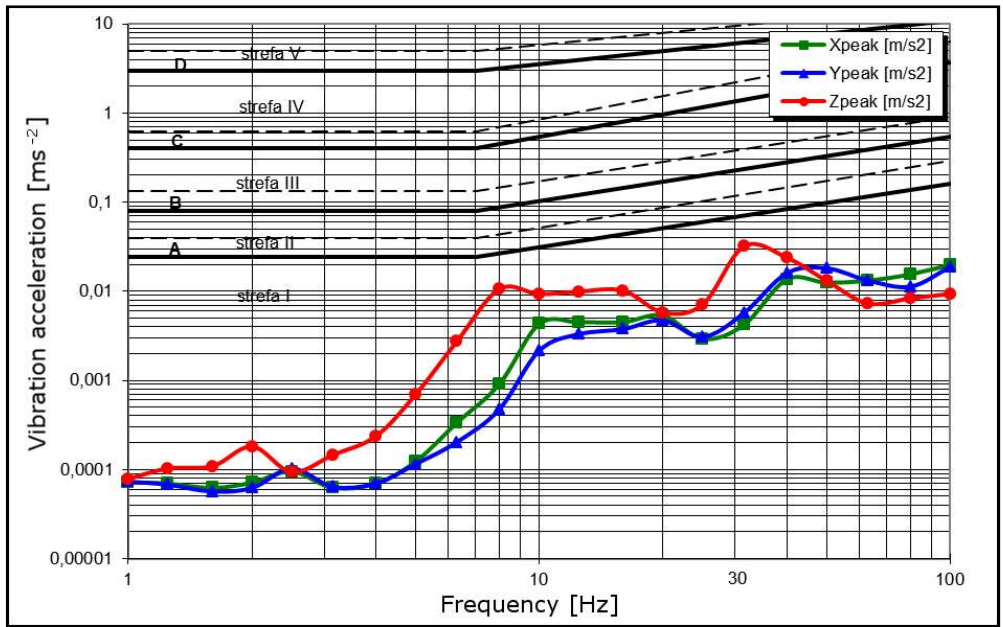

Fig. 13. The results of measurements of the impact of vibrations on building in $1 / 3$-octave bands for all axes at point PD2 (SWD II scale).

At point PD3, i.e. located in the central part of the largest storey room of the building (attic), the measurements did not show the negative (harmful) impact of vibrations on people staying in the building for the time of day and the time of night. The highest vibration values occurred in the vertical axis $(Z)$. The highest values of vibration accelerations at the PD1 
point and at the PD2 point occurred at $31.5 \mathrm{~Hz}$ frequency and at $50 \mathrm{~Hz}$, respectively. At the PD3 point the highest values of vibration accelerations occurred at $40 \mathrm{~Hz}$.

\section{Feasibility study and discussion on the reconstruction of the last overground storey and the utility attic of analysed building.}

The conducted research and analysis show that construction works related to the excavation of tunnels for the second underground line did not have a significant, harmful and direct impact on the development of the existing damage to the structural and building elements of the building located at No. 31 in Dobra Street in Warsaw. The carried out in-situ measurements of vibrations caused by both the traffic and the underground confirm, that there was no significant and harmful impact of the above mentioned factors on both damaged (scratched and cracked) supporting structure of the building and people in the building during daytime and night. The existing poor technical state of the building enables the future reconstruction of its last overground storey and the utility attic, while meeting the several conditions:

- the reinforcement of the subsoil under the foundations to avoid excessive settlement - the jet-grounding method is proposed,

- re-walling the damaged sections of the masonry supporting wall,

- the reinforcement of damaged elements of the supporting structure of this building,

- the reinforcement of load-bearing walls by their surface reinforcement - the surface reinforcement with steel bars in the shape of the spiral is recommended for all observed cracks. This method is described in detail in paper [11],

- tensioning the supporting structure with horizontal and vertical clasps,

- the positive recommendation for conducting planned construction works in the form of expertise of both adjacent buildings, including their inspections concerning their technical state.

\section{Conclusions}

From our studies the following conclusions can be formulated:

- The superstructure of historic buildings with additional storeys is possible, however, in each case a detailed assessment of the technical condition as well as the verification and calculation of internal forces and stresses in the structural elements of the building and its foundation are required. In the analysed case, the planned superstructure is a reconstruction of the shape and form of the building from the time before the war damage, which additionally confirms its feasibility.

- While in technical terms the construction of the additional overground storeys of the building is possible, the authors' experience with the similar implementations shows that it is not always profitable. The costs of the renovation works, the reinforcement of the existing structure of the building and works related to the superstructure itself may exceed the value of new usable areas and the new real estates.

- The construction works related to the excavation of tunnels for the second underground line did not have a significant, harmful and direct impact on the development of the damage to the structural and building elements of the building located at No. 31 in Dobra Street in Warsaw. It should be mentioned that regardless of the fact that the residents sense vibrations, the carrying-out detailed studies and measurements allow only to determine the possible impact of the construction works and traffic on the building and its residents. 
- The carried-out calculations confirmed that it is possible to reconstruct the last overground storey and the utility attic of the analysed building. However, this requires to conduct a detailed structural health assessment of the adjacent buildings and to ensure their constant monitoring during works (e.g. the network of control benchmarks). In addition, while carrying out works that could cause vibrations, it is advisable to conduct the measurements of vibrations analogous to those presented in this paper. It is also recommended to reinforce all damaged elements of the masonry construction. Performing these recommendations should allow an expert to objectively assess the impact of the construction works on the nearby facilities and should ensure the safety of this works.

\section{References}

1. R. Chmielewski, L. Kruszka, Case Studies in Construction Materials, 3, p.92-101 (2015). https://doi.org/10.1016/j.cscm.2015.08.001

2. www.geoportal.gov.pl

3. www.mapa.um.warszawa.pl

4. warszawa.ap.gov.pl

5. Instruction of Research Building Institute on building damage scales (ITB, Warszawa, 2006), in Polish.

6. K. Michalik, Technical expertise and diagnostics in building engineering (Prawo i Budownictwo, Chrzanów, 2014), in Polish.

7. Z. Tyczyński, Technical expertise No 68/2006 on assessment of the technical condition of a multi-family residential building at ul. Dobra 31 in Warsaw (Warszawa 2006), in Polish.

8. W. Wolski, Catalog card of the building No. 4.19 at ul. Dobra 31 in Warsaw (GEOTEKO Projekty i Konsultacje Geotechniczne Sp. z o.o., Warszawa, 2007), in Polish.

9. Catalog card of the building No C-50 at ul. Dobra 31 in Warsaw (AGP Metro Polska SC, Warszawa, 2010), in Polish.

10. L. Wysokiński, W. Kotlicki, Protection of buildings in the vicinity of deep excavations, Instruction No 376 (ITB, Warszawa, 2006), in Polish.

11. R. Chmielewski, L. Kruszka, J. Lalka, Biuletyn WAT, 684, 4, p.123-141 (2016), in Polish. 